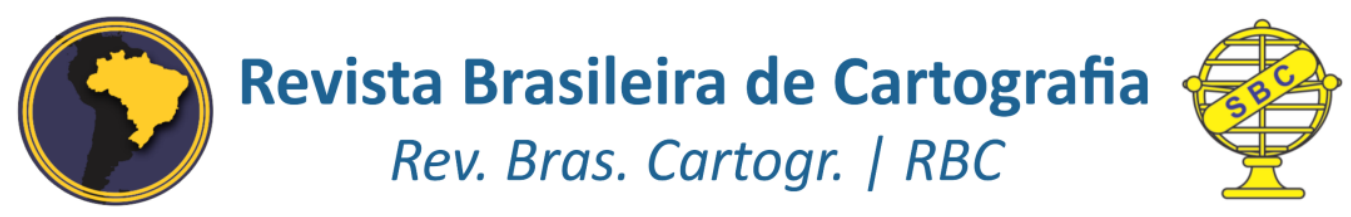

DOI: http://dx.doi.org/10.14393/rbcv71n3-47035

\title{
Zoneamento de Risco Climático do Cultivo da Nogueira Pecã (Carya illinoinensis) para o Rio Grande do Sul
}

\author{
Climate Risk Zoning of Pecan Cropping (Carya illinoinensis) in Rio Grande \\ do Sul
}

\begin{abstract}
Franciele Francisca Marmentini Rovani ${ }^{1}$ Cássio Arthur Wollmann ${ }^{2}$
\end{abstract}

Recebido em fevereiro de 2019. Aprovado em julho de 2019.

\begin{abstract}
RESUMO
A pesquisa teve como objetivo elaborar o zoneamento de risco climático do cultivo da nogueira pecã (Carya illinoinensis) para o Rio Grande do Sul. Foram coletados dados climatológicos e das fases fenológicas do cultivo, organizados e espacializados por meio da krigagem ordinária e integrados por meio da álgebra de mapas do aplicativo ArcGis 10.2.2. Como resultado destacam-se cinco índices de risco: falta de horas de frio no período de dormência; excesso de precipitação pluviométrica na expansão foliar, na floração e no desenvolvimento dos frutos; temperatura máxima superior a $35^{\circ} \mathrm{C}$ na floração e desenvolvimento dos frutos; excesso de umidade relativa do ar na floração; e estiagem no período de crescimento da nogueira. A dinâmica das variáveis climáticas aponta satisfação dos requerimentos climáticos do cultivo da nogueira pecã no Estado. O território apresentou $48,4 \%$ da área com risco muito baixo e $51,6 \%$ com risco baixo, indicando que o cultivo da nogueira pecã apresenta grande potencial para desenvolvimento no Rio Grande do Sul.
\end{abstract}

PALAVRAS-CHAVE: Índices climáticos. Mapeamento. Sistemas de Informações Geográficas.

\begin{abstract}
The objective of this research was to elaborate the climatic risk zoning of pecan cropping (Carya illinoinensis) for Rio Grande do Sul state. Were collected of climate data and cropping phenological phases, was organized and spatialized using ordinary kriging and integrated through map algebra in ArcGis software 10.2.2. Each climate risk was classified in very low, low, medium, high and very high. As a result five risk indices: lack of chilling in the dormancy period, excess rainfall at the foliar expansion,
\end{abstract}

${ }^{1}$ Professora Adjunta no Colégio Politécnico da Universidade Federal de Santa Maria, Brasil. E-mail: franciele.rovani@ufsm.br

${ }^{2}$ Professor Adjunto no Departamento de Geociências da Universidade Federal de Santa Maria. Programa de Pós-graduação em Geografia, Brasil. E-mail: cassiogeo@yahoo.com.br 
flowering and fruits formation; temperature above $35^{\circ} \mathrm{C}$ at the flowering and fruits formation; excess relative humidity at the flowering; and drought at the pecan growth period. The dynamics of climate variables in the state territory indicate that pecan climatic requirements is attended. The State presented $48.4 \%$ of the area with very low risk and $51.6 \%$ with low risk. This means that this cropping has great potential for development in Rio Grande do Sul state.

KEYWORDS: Climate index. Mapping. Geographic Information System.

\section{Introdução}

As relações existentes entre o clima e as plantas são determinantes para identificar o tipo de cultivos agrícolas e/ou espécies vegetais a serem cultivadas em diferentes espaços geográficos, segundo seus níveis de tolerância. Os fenômenos climáticos adversos constituem-se em eventos capazes de produzir, direta ou indiretamente, danos materiais, para as pessoas e para a produção agrícola. Mota e Agendes (1986) salientam que a seca e as estiagens são os maiores fenômenos adversos da agricultura brasileira tanto no Nordeste, como no Sul, Sudeste e Centro-Oeste, seguido das geadas e dos excessos hídricos. As variações extremas no clima influenciam fortemente na produtividade das culturas (SPARKS, 1996).

O Zoneamento de Risco Climático visa identificar e espacializar as áreas mais favoráveis para o desenvolvimento dos cultivos agrícolas e as áreas mais predispostas à ocorrência de fenômenos adversos durante as fases fenológicas do cultivo. Este zoneamento pode ser definido como um instrumento de gestão de riscos da agricultura e para sua elaboração é necessário analisar as variáveis de clima, solo e planta, objetivando quantificar o risco de perda das lavouras com base no histórico de ocorrência de eventos climáticos adversos (MAPA, 2010).

Dentre alguns cultivos agrícolas que merecem evidência pela carência de estudos científicos que enfoquem seu desenvolvimento e o seu potencial de expansão está o cultivo da nogueira pecã (Carya illinoinensis). Para este 
cultivo, os fenômenos adversos como falta de horas de frio, temperaturas superiores a $35^{\circ} \mathrm{C}$, secas ou estiagens, excesso de precipitação e umidade relativa do ar destacam-se.

A falta de horas de frio no período de dormência das plantas resulta em brotações deficientes com folhas raquíticas e poucas ramificações, floração irregular e o rendimento tende a ser muito abaixo do potencial (GRAGEDA et al., 2013). As temperaturas superiores a $35^{\circ} \mathrm{C}$ são prejudiciais, pois reduzem o crescimento vegetativo da nogueira pecã, aumentam a queda prematura dos frutos, diminuem seu tamanho e o acúmulo de óleo (RASEIRA, 1990) e interfere na polinização, em função de que existe um alto risco do pólen desidratar-se, conforme Grageda et al. (2013).

Além disso, a ocorrência de secas e condições de umidade inadequada do solo durante os meses dezembro a fevereiro, durante a elongação e expansão dos frutos e formação da amêndoa, resulta em nozes pequenas ou mal preenchidas (SPARKS, 1996). As precipitações excessivas no período de florescimento podem prejudicar a polinização (MOTA e ZAHLER, 1994). O desenvolvimento da amêndoa e sua qualidade poderão ser suprimidas devido às chuvas excessivas durante o período de crescimento (SPARKS, 1995; 1996). A umidade relativa do ar superior a $80 \%$ dificulta a liberação do pólen das flores masculinas resultando assim em menor fecundação e, além disso, aumenta as chances de ocorrência de enfermidades fúngicas (BRISON, 1976).

Assim, para a elaboração do Zoneamento de Risco Climático destacam-se o uso dos Sistemas de Informações Geográficas (SIGs), bem como da Geoestatística. Os SIGs potencializam a aquisição de dados geográficos, bem como de sua apreciação, alcançando a integração de informações geográficas em vários níveis temáticos (RIBEIRO, 2001). A integração das variáveis geográficas realizadas por meio de operadores lógicos e matemáticos, inerente à álgebra de mapas, possibilita a obtenção de resultados rápidos e confiáveis. 
Desta forma, diante na carência de estudos científicos que enfoquem o manejo do cultivo da nogueira pecã, especialmente do ponto de vista climático, o objetivo do trabalho foi elaborar o zoneamento de risco climático do cultivo da nogueira pecã (Carya illinoinensis) para o Rio Grande do Sul. A área de estudo compreende todo o Estado, onde a produção de nozes está em constante expansão.

\section{Materiais e Métodos}

Para a realização desta pesquisa foram coletados dados referentes ao cultivo da nogueira pecã, isto é, dados de requerimentos climáticos e de fenologia das regiões de origem do cultivo e do estado do Rio Grande do Sul. Foram definidos os índices de risco climático para diferentes fases fenológicas. Na sequência, elaborou-se o banco de dados geográficos com o aplicativo ArGis 10.2.2, cujas ferramentas de análise espacial foram empregadas para obtenção do zoneamento de risco climático.

Os dados de exigências climáticas e de fenologia da planta nas fases de desenvolvimento vegetativo, reprodutivo e senescência foram obtidos junto a pesquisas científicas, empresas de produção e beneficiamento das nozes e técnicos da Empresa de Assistência Técnica e Extensão Rural -RS (EMATER-RS) nos principais municípios produtores. A identificação das principais variedades cultivadas e dados sobre adaptações aos diferentes ambientes foram obtidos em referências internacionais.

Os dados climáticos em escala diária e horária foram obtidos em um recorte temporal de 15 anos, isto é de 1998 a 2013, exceto o ano de 2001, junto às 23 estações convencionais da rede do Instituto Nacional de Meteorologia (INMET) localizadas no Estado (Figura 1). 
Figura 1 - Localização das estações meteorológicas no estado do Rio Grande do Sul

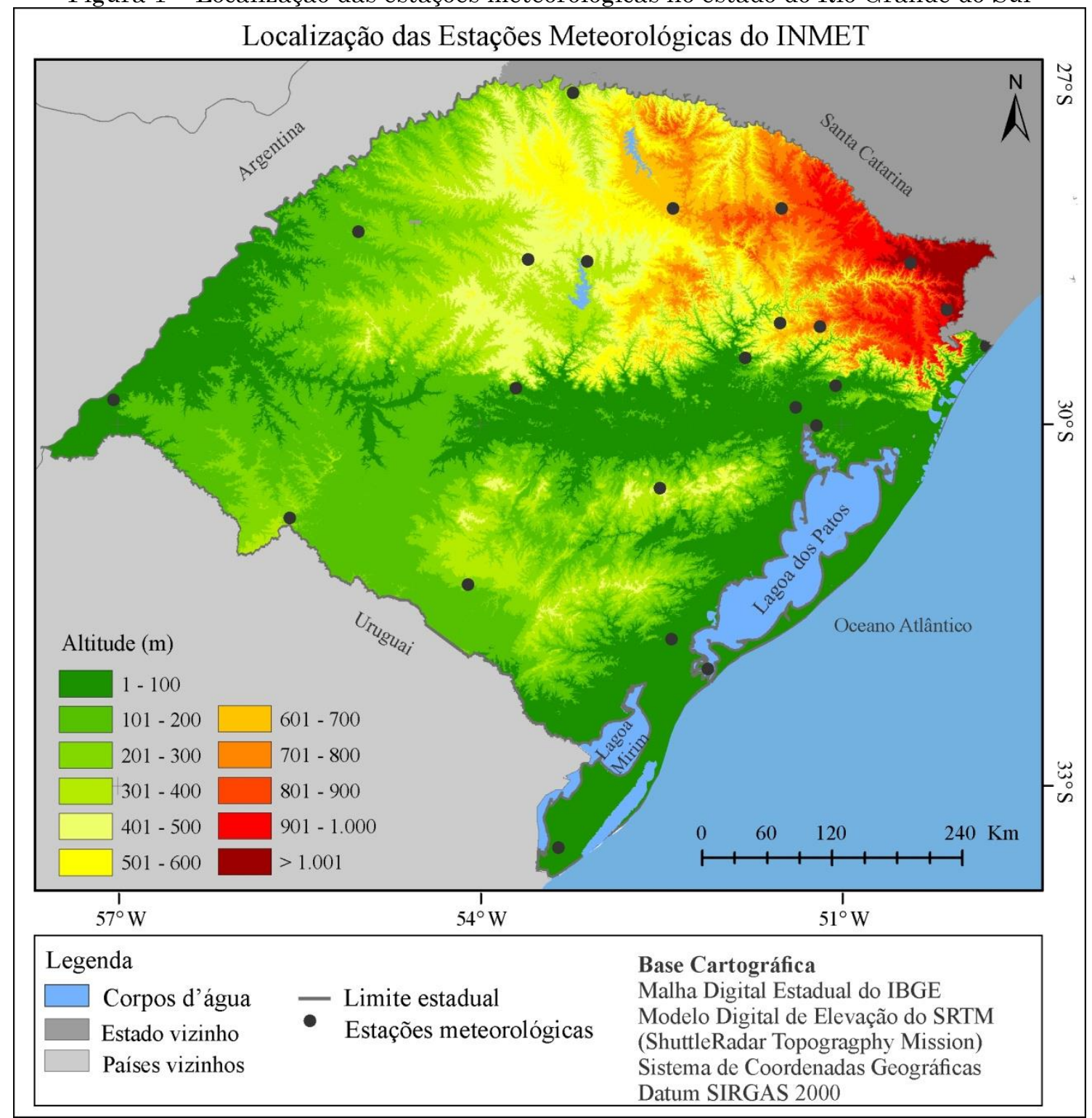

Fonte: Elaborada pelos autores.

As variáveis climáticas coletadas constaram da temperatura média, temperatura máxima e mínima absoluta, precipitação pluviométrica e umidade relativa do ar. A coleta dos dados nas estações meteorológicas convencionais do INMET foi realizada nos horários de 12, 18 e 24 UTC (Coordinated Universal Time). Os dados foram organizados em planilhas do Microsoft Office Excel por variável climática diária no período histórico de todas as 23 estações meteorológicas. Os dados relativos ao número de horas 
de frio, definidas como temperaturas iguais ou abaixo de $7,2{ }^{\circ} \mathrm{C}$, foram obtidos por meio do mapa de horas de frio elaborado por Herter et al. (2002).

Para obtenção dos índices de risco climático utilizou-se a variável climática diária de temperatura máxima absoluta, umidade relativa do ar, precipitação pluviométrica e número de horas de frio. A determinação dos riscos climáticos, bem como os valores aceitáveis baseou-se nas características climáticas da área de estudo, juntamente com as características da região de origem da nogueira, fundamentalmente embasados nos estudos desenvolvidos por Sparks (1996; 1997; 2005) e Sierra, López e Pérez (2007). Estes estudos permitiram definir os valores aceitáveis para os requerimentos de precipitação, temperatura e número de horas de frio. Para a umidade relativa do ar observou-se as indicações de Brison (1976). Deste modo, estabeleceram-se para cada risco climático os valores mínimos e máximos aceitáveis, podendo assim enquadrar as áreas em cinco classes de risco: muito baixo, baixo, médio, alto e muito alto (Quadro 1). As áreas que apresentaram atendimento dos requerimentos climáticos foram classificadas na classe sem risco.

Quadro 1 - Classificação do risco climático, peso atribuído e caracterização da área de acordo com o risco

\begin{tabular}{|c|c|c|}
\hline $\begin{array}{c}\text { Classificação do risco } \\
\text { climático }\end{array}$ & Peso & Caracterização da área \\
\hline Muito Baixo & 1,0 & \multirow{2}{*}{$\begin{array}{l}\text { Áreas com melhores condições para o cultivo } \\
\text { da nogueira pecã, porém podendo ocorrer } \\
\text { fatores adversos para o cultivo. }\end{array}$} \\
\hline Baixo & 2,0 & \\
\hline Médio & 3,0 & $\begin{array}{l}\text { Áreas em que predominam índices de risco } \\
\text { moderado, que podem influenciar na } \\
\text { produtividade. }\end{array}$ \\
\hline Alto & 4,0 & \multirow{2}{*}{$\begin{array}{l}\text { Áreas menos indicadas para o cultivo, em } \\
\text { que a produtividade poderá ser baixa e } \\
\text { afetar o cultivo por um ou mais anos. }\end{array}$} \\
\hline Muito Alto & 5,0 & \\
\hline
\end{tabular}

Fonte: Elaborado pelos autores.

Os riscos climáticos à cultura da nogueira pecã, no Rio Grande do Sul, foram dispostos em cinco índices, a saber: falta de horas de frio, 
temperaturas superiores a $35^{\circ} \mathrm{C}$, excesso de precipitação, estiagens e excesso de umidade relativa do ar.

a) Falta de horas de frio - Considerou-se temperaturas inferiores a $7,2^{\circ} \mathrm{C}$ no período de dormência das plantas (maio a setembro).Os índices, expressos em horas (h), foram dispostos nas seguintes classes: 250 a $300 \mathrm{~h}$ baixo;300 a $350 \mathrm{~h}$ - muito baixo;200 a $250 \mathrm{~h}$ - médio; 150 a $200 \mathrm{~h}$ - alto e abaixo de $150 \mathrm{~h}$ - muito alto.

b) Temperaturas superiores a $35^{\circ} \mathrm{C}$ - Os índices foram baseados no número de dias em que a temperatura máxima (Tmáx) foi superior a $35^{\circ} \mathrm{C}$ durante o período de polinização e floração (outubro a novembro) e de formação dos frutos (janeiro e fevereiro). Os índices considerados foram: até 2 dias - muito baixo; até 3 dias - baixo; até 4 dias - médio; até 5 dias - alto e maior que 5 dias - muito alto.

c) Excesso de precipitação - Os índices foram obtidos considerando os períodos de expansão foliar (setembro e outubro), de floração e polinização (outubro e novembro) e de formação dos frutos (dezembro, janeiro e fevereiro) com base na pluviosidade em dias consecutivos de ocorrência: durante 2 dias - muito baixo; até 3 dias - baixo; até 4 dias - médio; até 5 dias: alto e superior a 5 dias - muito alto.

d) Risco de estiagem - Os índices foram obtidos em relação à pluviosidade ocorrida durante a estação de crescimento da nogueira (outubro a abril) que compreende os estágios fenológicos de floração (outubro e novembro), formação e maturação dos frutos (dezembro a abril): pluviosidade entre 687,5 a $750 \mathrm{~mm}$ - muito baixo; de 625 a $687,5 \mathrm{~mm}$ - baixo; de 562,5 a $625 \mathrm{~mm}$ - médio; de 500 a $562,5 \mathrm{~mm}$ - alto e inferior a $500 \mathrm{~mm}$ muito alto.

e) Excesso de umidade relativa do ar - Os índices foram obtidos no período de floração e polinização (outubro e novembro) com base na ocorrência de dias consecutivos com umidade relativa do ar acima de 80\%: inferior a 4 dias - muito baixo; 5 dias - baixo; 6 dias - médio; 7 dias - alto e 8 dias ou mais - muito alto. 
O intervalo entre cada classe foi definido por meio da amplitude (diferença entre o valor mínimo e máximo) pelo número de classes, quando houvesse, ou pela frequência da ocorrência do número de dias com incidência do risco. Para todas as classes de risco atribuiu-se um peso. Os índices de risco de temperaturas superiores a $35^{\circ} \mathrm{C}$, excesso de precipitação e excesso de umidade relativa do ar, que poderiam apresentar diferentes classes para a mesma estação meteorológica, realizou-se uma média ponderada a fim de obter o valor final do índice. Atribuiu-se pesos que variaram de 1 a 5 seguindo a ordem de risco muito baixo e até o muito alto, porque entende-se que quanto maior o número de ocorrências com dias consecutivos maior será o risco para o cultivo.

Para a espacialização dos índices de risco nas diferentes fases fenológicas da nogueira pecã utilizou-se a interpolação pelo método da krigagem ordinária (com modelo de semivariograma esférico). Este método foi escolhido, pois apresentou menor erro quadrático médio quando testado com os interpoladores pelo inverso do quadrado da distância e spline. A variável visual utilizada foi a cor, em que as áreas com risco baixo foram representadas em tons de verde e as áreas com risco alto em tons de vermelho.

De posse de todos os índices espacializados, a integração destes, que resultou no mapa do Zoneamento de Risco Climático, ocorreu por meio da ferramenta de álgebra de mapas. Para os índices que foram avaliados em mais de um estágio fenológico, realizou-se a média aritmética simples para obter uma única representação do índice em estudo. Desta forma, a partir dos cinco índices de risco climático, utilizou-se novamente a média aritmética simples, no qual a atribuição das classes, em função dos pesos obtidos, deu-se conforme o quadro 1. A classe de risco baixo, presente no zoneamento, foi divida em A e B, para enfatizar a ocorrência, sobretudo, do índice de falta de horas de frio, na região que compreende a fronteira do Rio Grande do Sul com a Argentina, o que não acontece no restante da região classificada. 


\section{Resultados e Discussão}

O Zoneamento de Risco Climático da nogueira pecã é resultado da integração, isto é, da síntese das informações obtidas a partir dos cinco índices de riscos definidos para as diferentes fases fenológicas do cultivo. A figura 2 apresenta o índice de risco de temperaturas superiores a $35^{\circ} \mathrm{C}$ na floração (A) e na formação dos frutos (B), o índice de risco de falta de horas de frio no período de dormência da nogueira pecã (C) e o índice de risco de excesso de umidade na floração (D).

Figura 2 - Índice de risco de temperatura superior a $35^{\circ} \mathrm{C}$ na floração (A) e na formação dos frutos (B), índice de risco de falta de horas de frio no período de dormência (C) e índice de risco de excesso de umidade na floração (D)

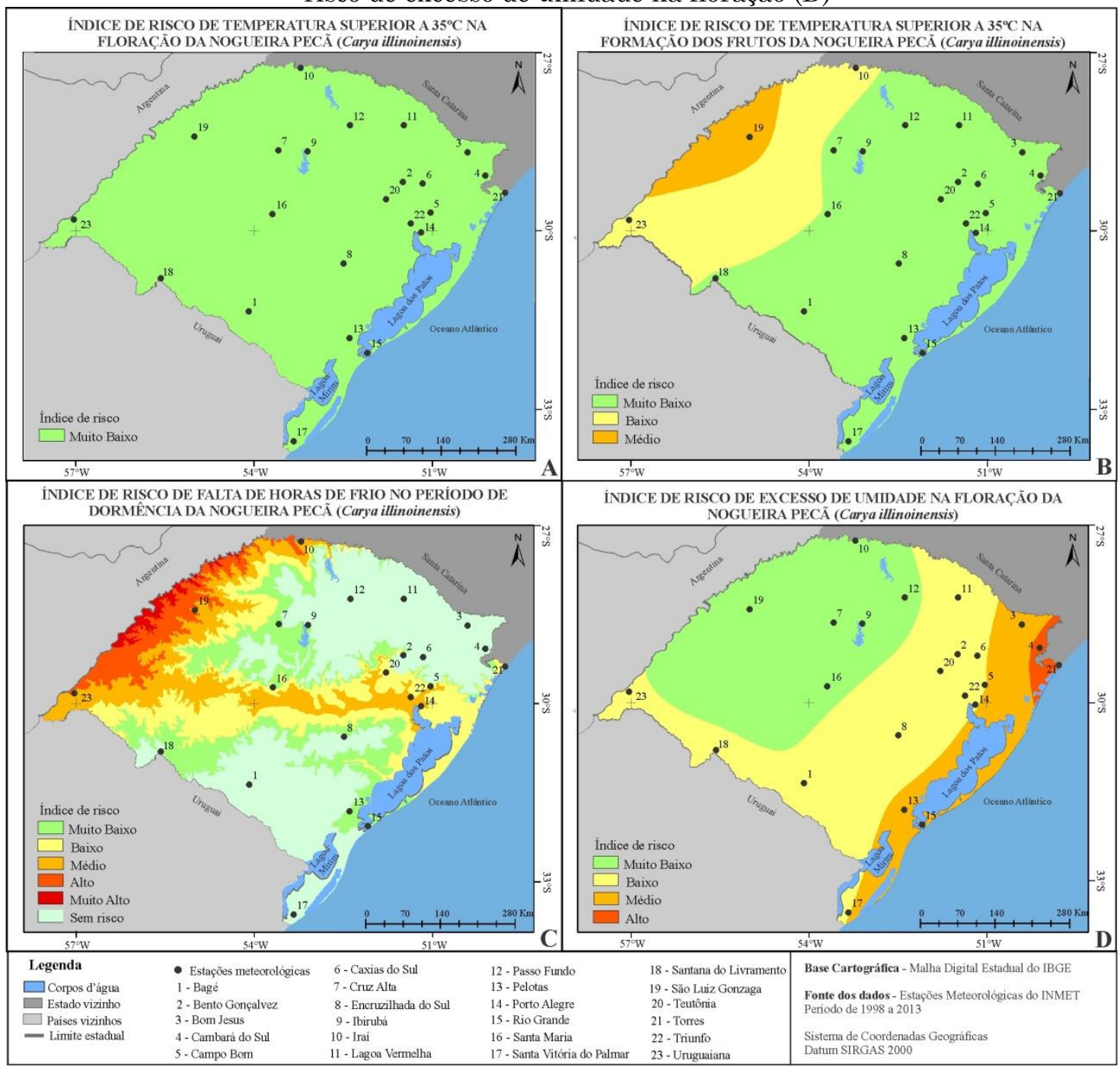

Fonte: Elaborada pelos autores. 
$\mathrm{O}$ índice de risco de temperatura superior a $35^{\circ} \mathrm{C}$ na floração (Figura 2A) foi considerado muito baixo para todo o Estado, ou seja, prevaleceu a ocorrência de temperaturas superiores a $35^{\circ} \mathrm{C}$ até dois dias durante os meses de outubro e novembro. Esse índice de risco muito baixo pode apresentar pouca interferência na floração, mas tende a aumentar a sua influência à medida que a frequência de temperaturas superiores a $35^{\circ} \mathrm{C}$ aumenta. Segundo Grageda et al. (2013), essas temperaturas interferem na polinização e na floração, bem como na formação dos frutos, resultando em poucos frutos por ramos, em função de que existe um alto risco do pólen desidratar-se.

$\mathrm{O}$ índice de risco de temperaturas superiores a $35^{\circ} \mathrm{C}$ na formação dos frutos da nogueira pecã (Figura 2B) mostra a presença de três classes de risco: muito baixo, baixo e médio. $\mathrm{O}$ risco muito baixo, temperaturas superiores a $35^{\circ} \mathrm{C}$ até dois dias, compreende $67,4 \%$ da área de estudo, isto é, a maior parte, com exceção da fronteira noroeste do Estado, com a Argentina e parte com o Uruguai. Dentre os 20 maiores municípios produtores de nogueira pecã no Estado, destacam-se, nessa classe, Vila Nova do Sul, Santa Maria, Cachoeira do Sul, Rio Pardo, General Câmara, Anta Gorda.

$\mathrm{O}$ risco baixo, temperaturas superiores a $35^{\circ} \mathrm{C}$ até três dias, representa $25,2 \%$ da área total, compreendendo a região de Uruguaiana em direção a Iraí, ao norte. Uma pequena região, na fronteira com a Argentina, incluindo São Luiz Gonzaga representa $7,4 \%$ do total, com risco médio e temperaturas superiores a $35^{\circ} \mathrm{C}$ até quatro dias. De acordo com Raseira (1990), essas temperaturas elevadas são prejudiciais, pois podem reduzir o crescimento vegetativo da nogueira pecã, aumentar a queda prematura dos frutos, diminuir o seu tamanho e o acúmulo de óleo.

$\mathrm{O}$ índice de risco de falta de horas de frio (Figura 2C) foi elaborado para o período de dormência da nogueira pecã. De acordo com a representação, verifica-se a existência das cinco classes de risco em $57,5 \%$ do território gaúcho e duas regiões, uma ao norte e outra ao sul, sem a presença de risco, representando $42,5 \%$ da área total. O risco muito baixo, que 
compreende as áreas situadas entre 300 e 350 horas de frio, representa 15,5\% da área total. Nessa área, pode-se destacar os municípios produtores de nozes de Vila Nova do Sul, Quevedos e Rondinha.

O risco baixo, entre 250 e 300 horas de frio, ocupa 20,2\% da área, ou seja, maior proporção de área ocupada pelos riscos. A faixa compreendida entre 200 e 250 horas foi classificada de risco médio e representa 13,7\% da área. Alguns dos maiores municípios produtores de nozes encontram-se localizados nessas duas áreas: São Vicente do Sul, Santa Maria, Cachoeira do Sul, Rio Pardo, Cruzeiro do Sul e General Câmara. O risco alto $(6,4 \%)$ que compreende horas de frio entre 150 a 200 , e muito alto $(1,7 \%)$, com horas de frio inferiores a 150, apresentaram as menores proporções. Na área de risco alto, destacam-se os municípios de Iraí e Crissiumal e, na de risco muito alto, os municípios fronteiriços tais como São Borja, Garrujos, Porto Xavier, Itaqui e Roque Gonzáles.

As regiões que não apresentaram risco, ou seja, que possuem mais que 350 horas de frio estão localizadas nas regiões sul e noroeste do Estado. A primeira atende o número de horas de frio, pois a sua localização está relacionada com a interferência da latitude nas temperaturas e, na segunda, as horas de frio estão mais relacionadas com a interferência da altitude. Dentre os principais municípios produtores de nozes e que estão situados fora das áreas de risco tem-se os territórios de Anta Gorda, Nova Petrópolis, Arvorezinha, Ciríaco, Tapejara, Rondinha e Barão do Triunfo.

O número de horas de frio corresponde à quantidade de frio requerida para o término do repouso e o início de um novo ciclo, o vegetativo/reprodutivo, que ocorre somente após as plantas sofrerem a ação das baixas temperaturas. Conforme destacado por Sentelhas e Angelocci (2009), as espécies frutíferas de clima temperado, de folhas caducas, apresentam um período de repouso invernal, durante o qual não apresentam crescimento vegetativo, em que as condições climáticas atuam sobre os reguladores de crescimento. Assim, a temperatura é reconhecidamente um fator muito importante no balanço hormonal dessas frutíferas. 
$\mathrm{O}$ índice de risco de excesso de umidade relativa do ar, conforme a figura 2D, foi elaborado para o período de floração e polinização da nogueira, durante os meses de outubro e novembro. Observando a representação, verifica-se a presença de quatro classes de risco. Em 42,9\% do Estado, destaca-se o risco muito baixo, ou seja, umidade relativa superior a $80 \%$ durante três a quatro dias consecutivos, nas regiões que compreendem Santa Maria, São Luiz Gonzaga, Cruz Alta, Ibirubá, Passo Fundo e Iraí. Em proporção aproximada, 42,2\%, apresenta o risco baixo, umidade relativa superior a $80 \%$ durante cinco dias consecutivos, nas regiões de Uruguaiana, Santana do Livramento, Bagé, Encruzilhada do Sul, Triunfo, Campo Bom, Teutônia, Bento Gonçalves, Caxias do Sul e Lagoa Vermelha.

O risco médio, umidade relativa superior a $80 \%$ durante seis dias, destaca-se em 13,2\% do território, principalmente nas regiões litorâneas de Santa Vitória do Palmar, Rio Grande, Pelotas e Bom Jesus. O risco alto, umidade relativa superior a $80 \%$ durante sete dias consecutivos, representa 1,7\% da área nas regiões que compreendem Torres e Cambará do Sul, com forte influência da umidade marítima. Nessa área, ainda não há registro de municípios produtores de nozes.

De acordo com o resultado obtido na representação do índice de risco de excesso de umidade, pode-se afirmar que a região que compreende o risco médio e alto merece especial atenção, pois predominam condições desfavoráveis para a floração e favoráveis para a incidência de doenças fúngicas. Nestas zonas recomenda-se o plantio de diversas variedades nos pomares de nogueiras e variedades mais resistentes a umidade. Assim, as chances de polinização serão aumentadas e favorecidas, se houver a incidência de vento.

O excesso de umidade, além de limitar o deslocamento do pólen, aumenta as chances de ocorrências da sarna, que é beneficiada por chuvas frequentes, alta umidade e temperaturas acima de $21^{\circ} \mathrm{C}$ (HEEREMA, GOLDBERG e THOMAS, 2010). Concordando com Fronza e Hamann (2016), a sarna compromete os tecidos jovens em crescimento, tais como 
folhas, pecíolos, epicarpo dos frutos e amentos, podendo causar prejuízos de 50 a $100 \%$, em períodos de elevada umidade.

O índice de risco de excesso de precipitação (Figura 3) foi identificado e elaborado para três fases fenológicas do cultivo, ou seja, na expansão foliar (A), na floração (B) e na formação dos frutos da nogueira (C). O índice de risco de estiagem no período de crescimento da nogueira é apresentado na figura 3D.

Figura 3 - Índice de risco de excesso de precipitação na expansão foliar (A), na floração (B) e na formação dos frutos da nogueira (C) e índice de risco de estiagem no período de crescimento da nogueira (D)

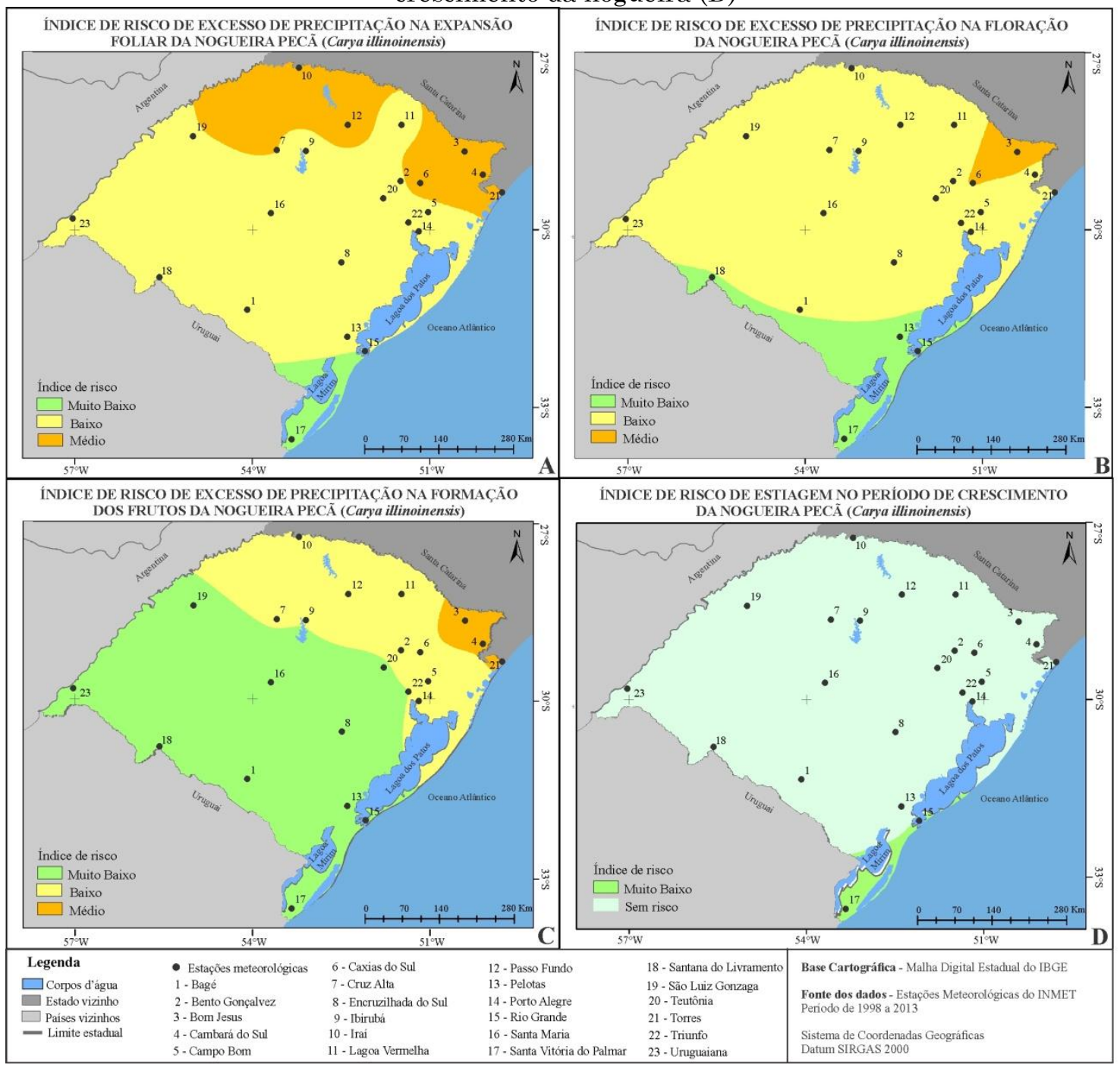

Fonte: Elaborada pelos autores. 
De acordo com a figura $3 \mathrm{~A}$, verifica-se a presença das classes de risco muito baixo, baixo e médio para o índice de excesso de precipitação na expansão foliar. O risco muito baixo com precipitações consecutivas durante dois dias incide em $4 \%$ da área estadual, restringindo-se ao sul, em Santa Vitória do Palmar e Rio Grande. Nessa área, ainda não há registro de municípios produtores de noz pecã. Na maior parte do Estado, 72,9\% do território, destaca-se a incidência do baixo risco, com precipitações consecutivas até três dias. Nessa área, estão incluídos alguns dos maiores municípios produtores de nozes, tais como Santa Maria, Cachoeira do Sul, Anta Gorda, General Câmara, Cruzeiro do Sul e São Vicente do Sul.

Destacam-se também, duas regiões, uma ao norte, junto a Iraí e Passo Fundo, e outra a leste, envolvendo Cambará do Sul, Bom Jesus e Torres, que apresentaram risco médio $(23,1 \%)$, com precipitações consecutivas até quatro dias. Destacam-se, nessa área de risco médio os municípios produtores de Nova Petrópolis, Ajuricaba, Rondinha, Tapejara, Crissiumal e Iraí. Essas áreas requerem maior atenção, pois aumentam as chances do aparecimento de doenças fúngicas.

Conforme destaca Sparks (1997), dois dias consecutivos ou mais de precipitação no período de expansão foliar, bem como na formação dos frutos, favorecem a infestação pela sarna (Cladosporium carygenum) e outras doenças fúngicas. Essa doença, considerada a pior e mais frequente doença de folhas e frutos da nogueira pecã, afeta diretamente a sua produção do ano corrente e no ano posterior (RASEIRA, 1990; SPARKS, 1996).

O índice de risco de excesso de precipitação na floração da nogueira apresentou risco muito baixo em $11,7 \%$ da área territorial, baixo em $85 \%$ e risco médio em 3,3\% (Figura 3B). Conforme a representação, o risco muito baixo, precipitações consecutivas durante dois dias, bem como o risco baixo, precipitações consecutivas até três dias, aumentaram a sua área de ocorrência quando comparados com o índice de risco na expansão foliar. $\mathrm{Na}$ área de risco muito baixo, destacam-se três municípios produtores de 
nogueiras: Santana do Livramento, Candiota e Dom Pedrito. Por conseguinte, na área de influência de risco baixo de excesso de precipitação na floração, encontram-se $100 \%$ dos maiores municípios produtores de nozes. Já, o risco médio, com precipitações consecutivas até quatro dias, diminuiu a sua área de ocorrência, compreendendo os municípios de Caxias do Sul e Bom Jesus. Isso significa que o número de dias com precipitações consecutivas diminuiu e, com isso, menos períodos propícios para o desenvolvimento de fungos, tais como a sarna e a antracnose. Porém, as precipitações constantes no período de florescimento podem prejudicar a polinização (MOTA e ZAHLER, 1994), uma vez que é anemófila e requer a presença de ventos.

$\mathrm{O}$ risco muito baixo concentrou-se ao sul do Estado, nas regiões de Santana do Livramento, Bagé, Pelotas, Rio Grande e Santa Vitória do Palmar, sendo que essas áreas também apresentam os menores totais pluviométricos. O risco baixo prevaleceu em 85\% do Estado, excetuando as regiões anteriores e uma região a leste, que compreende principalmente Bom Jesus, que, apesar de não apresentar os maiores índices pluviométricos para esse período, apresentou o maior número de dias consecutivos com precipitação.

A ocorrência de fungos, como qualquer outro patógeno, está condicionada à disseminação por vetores, tais como o vento, a água, os insetos ou os animais (POLETTO et al., 2014). As condições climáticas podem favorecer a incidência de determinados patógenos e as flores podem gerar a transmissão dos fungos para os frutos, no momento de sua formação e, consequentemente, para as sementes (LAZAROTTO, 2013).

O índice de risco de excesso de precipitação na formação dos frutos, nos meses de dezembro, janeiro e fevereiro, também apresentou três classes (Figura $3 \mathrm{C}$ ). De acordo com a representação, destaca-se a presença do risco muito baixo em mais da metade do Estado (64,8\%), compreendendo parte da fronteira oeste com a Argentina, toda a fronteira com o Uruguai, parte da faixa litorânea, limitando-se com as regiões de Triunfo, Cruz Alta e São Luiz 
Gonzaga. Essa área compreende também os principais municípios produtores de nozes, especialmente São Vicente do Sul, Santa Maria, Cachoeira do Sul, Cruzeiro do Sul e Rio Pardo.

O risco baixo, precipitações consecutivas até três dias, representa $32,1 \%$ do total e compreende as regiões de Iraí, Ibirubá, Lagoa Vermelha, Bento Gonçalves, Caxias do Sul, Porto Alegre e Campo Bom. A região que compreende Bom Jesus, Cambará do Sul e Torres, apresenta risco médio, ou seja, precipitações consecutivas até quatro dias e está presente em $3,1 \%$ do território. Nessa região, ainda não há registro de municípios produtores de nogueiras.

A qualidade das nozes depende da precipitação adequada nesse período, que envolve desde a formação da casca até o preenchimento da amêndoa. As condições de secas podem produzir nozes pequenas, no entanto, as chuvas excessivas durante o período de alongamento dos frutos, bem como na expansão e no desenvolvimento da amêndoa, afetam a qualidade dos frutos e podem causar aborto deles (SPARKS, 1995; 1996).

$\mathrm{O}$ índice de risco de estiagem no período de crescimento das nozes compreende os estágios fenológicos de floração, formação, maturação e colheita dos frutos (Figura 3D). O índice de risco de estiagem no período de crescimento das nozes, meses de outubro a abril, apresentou somente a classe de risco muito baixo em $3,1 \%$ do território gaúcho. Isso indica que 96,9\% da área está situada fora dos valores do índice de risco, ou seja, com precipitações pluviométricas superiores a $750 \mathrm{~mm}$ nesse período. A região que compreende Santa Vitória do Palmar e Rio Grande apresentou o risco muito baixo, pois os totais pluviométricos para o período estiveram compreendidos entre 687,5 a $750 \mathrm{~mm}$.

Para Sierra, López e Pérez (2007), o mínimo de precipitação anual que a nogueira pecã tolera aproxima-se dos $750 \mathrm{~mm}$, enquanto que o máximo é de $2.000 \mathrm{~mm}$. Ainda segundo os autores, durante a estação de crescimento das nozes deve ocorrer no mínimo $500 \mathrm{~mm}$ de precipitação, já que, valores situados entre 750 a $500 \mathrm{~mm}$ necessitariam de uma irrigação complementar, 
dependendo do tipo de solo e regiões com precipitações abaixo de $500 \mathrm{~mm}$, demandariam irrigação total do pomar.

Precipitações inadequadas influenciam negativamente na qualidade das nozes, ou seja, a ocorrência de estiagens durante os meses de dezembro a fevereiro resultam em nozes pequenas ou mal preenchidas (SPARKS, 1995; 1996). As estiagens podem causar desfolhamento prematuro, o que suprime a formação da flor em árvores com grande frutificação, além de provocar o aborto dos frutos e alterações no tamanho e na forma da noz pecã (SPARKS, 1996).

A integração dos cinco índices de risco resultou no mapa final do Zoneamento de Risco Climático (Figura 4) e a porcentagem de área ocupada por cada índice de risco climático e o zoneamento pode ser observada na tabela 1.

Tabela 1 - Porcentagem de área ocupada por cada classe de índice de risco climático e o zoneamento para o estado do Rio Grande do Sul

\begin{tabular}{|c|c|c|c|c|c|c|}
\hline \multirow{2}{*}{$\begin{array}{l}\text { Índice de Risco/ } \\
\text { Zoneamento }\end{array}$} & \multicolumn{6}{|c|}{ Porcentagem de área ocupada (\%) } \\
\hline & $\begin{array}{c}\text { Sem } \\
\text { risco }\end{array}$ & $\begin{array}{l}\text { Muito } \\
\text { baixo }\end{array}$ & Baixo & Médio & Alto & $\begin{array}{l}\text { Muito } \\
\text { alto }\end{array}$ \\
\hline $\begin{array}{c}\text { Temperaturas } \\
\text { superiores à } 35^{\circ} \mathrm{C}\end{array}$ & & $92,4 \%$ & $7,6 \%$ & & - & \\
\hline $\begin{array}{c}\text { Falta de horas de } \\
\text { frio }\end{array}$ & $42,5 \%$ & $15,5 \%$ & $20,2 \%$ & $13,7 \%$ & $6,4 \%$ & $1,7 \%$ \\
\hline $\begin{array}{l}\text { Excesso de umidade } \\
\text { relativa do ar }\end{array}$ & - & $42,9 \%$ & $42,2 \%$ & $13,2 \%$ & $1,7 \%$ & \\
\hline $\begin{array}{c}\text { Excesso de } \\
\text { precipitação }\end{array}$ & - & $7,5 \%$ & $91,6 \%$ & $0,9 \%$ & - & - \\
\hline Risco de estiagem & $96,9 \%$ & $3,1 \%$ & - & - & - & - \\
\hline $\begin{array}{c}\text { Zoneamento de } \\
\text { risco climático }\end{array}$ & - & $41,8 \%$ & $58,2 \%$ & - & - & - \\
\hline
\end{tabular}

Fonte: Elaborada pelos autores. 
Figura 4 - Zoneamento de risco climático do cultivo da nogueira pecã (Carya illinoinensis) no Rio Grande do Sul

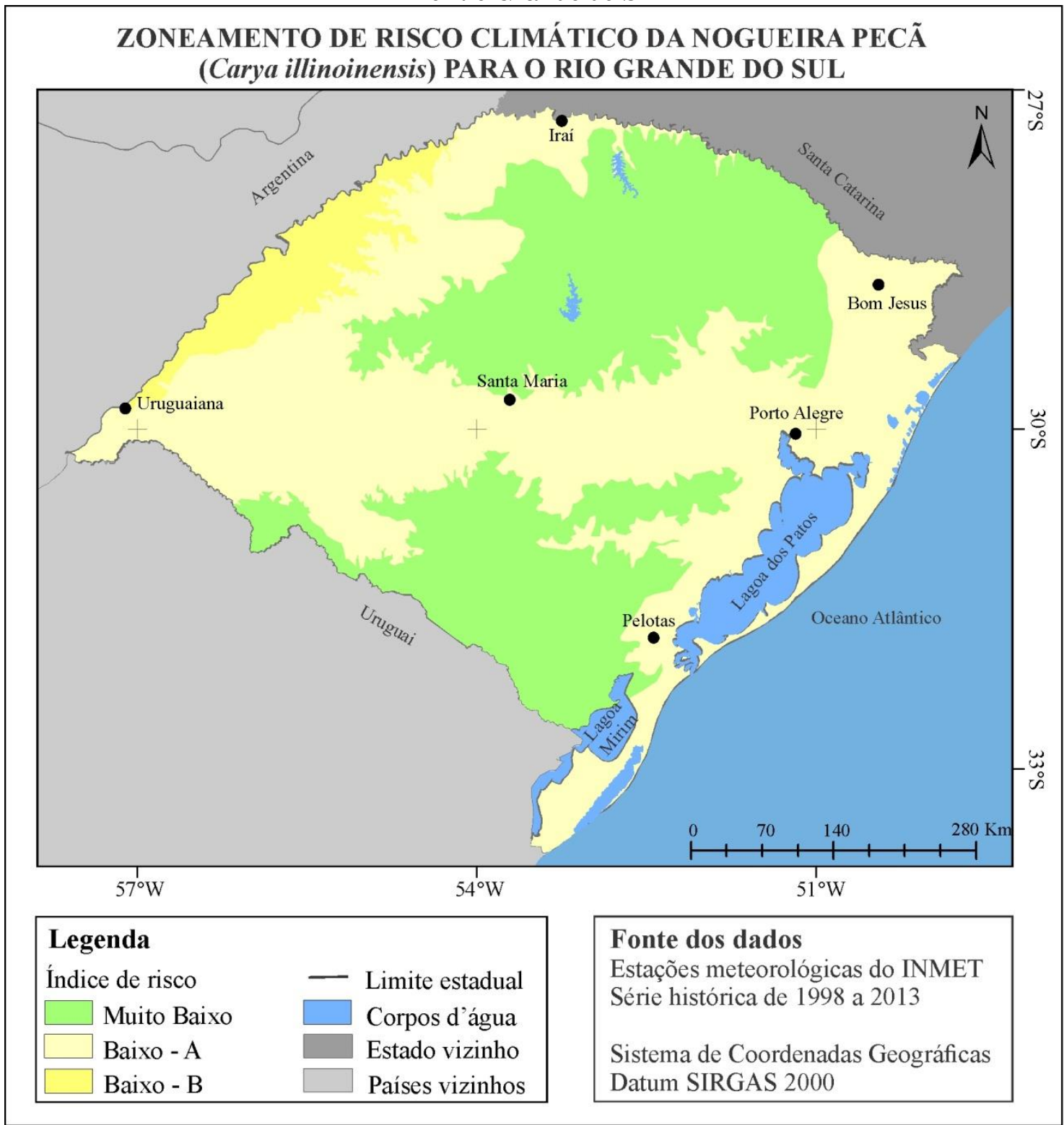

Fonte: Elaborado pelos autores.

De acordo com o mapa de Zoneamento verifica-se a presença de duas classes de risco: muito baixo e baixo. A classe de risco baixo foi subdividida em duas (baixo - A e baixo - B) para melhor destacar as características das regiões classificadas, pois, apesar de serem de risco baixo, apresentam diferenciações significativas quanto à presença dos cinco índices de risco analisados. 
A classe de risco muito baixo encontra-se em 41,8\% do território gaúcho e representa as áreas em que predominaram os índices de risco muito baixo ou a ausência de riscos. Nessas áreas, prevaleceu o risco baixo de excesso de precipitação, o risco muito baixo de temperaturas superiores a $35^{\circ} \mathrm{C}$ e os riscos muito baixo e baixo de excesso de umidade relativa do ar. Destaca-se ainda por ser a zona com ausência de estiagem e sem risco das horas de frio, sendo assim, a região mais indicada para o cultivo da nogueira pecã. Dentre os 20 maiores municípios produtores de nozes no Estado, destacam-se, nessa área, os municípios de Quevedos, Rondinha, Tapejara, Ciríaco, Arvorezinha, Anta Gorda, Nova Petrópolis e Barão do Triunfo.

A região com predomínio do risco baixo - A representa a maior parte do Estado, ou seja, $51,6 \%$ da área total. Abrange uma área bastante diversificada, tanto em latitude, como em longitude, que se estende desde o norte até o sul e de oeste até leste, em toda a faixa litorânea. Enfatiza-se a presença de risco muito baixo e baixo com relação às temperaturas superiores a $35^{\circ} \mathrm{C}$ e excesso de precipitação, respectivamente. Apresentou risco de estiagem ao sul e risco muito baixo a médio de falta de horas de frio. Por ser uma área de extensão longitudinal, apresentou todas as classes de risco do índice de excesso de umidade relativa do ar (muito baixo a alto). Destacam-se, nessa zona de risco baixo - A, os maiores municípios produtores de nogueiras tais como Santa Maria, Cachoeira do Sul, Rio Pardo, General Câmara, Cruzeiro do Sul e Iraí.

A classe de risco baixo - B destaca-se em uma pequena porção situada a noroeste do Estado, na fronteira com a Argentina, e representa 6,6\% da área total. Compreende basicamente a região de São Luiz Gonzaga e Uruguaiana e os municípios próximos ao Rio Uruguai. Essa região distinguiu-se da anterior pelo fato de apresentar o predomínio da falta das horas de frio, ou seja, apesar de representar uma área de baixo risco, no que se refere às necessidades de horas de frio, apresenta risco alto e muito alto. Por outro lado, apresenta ausência do risco de estiagem e risco muito baixo quanto ao índice de excesso de precipitação. Também destaca-se por 
apresentar risco baixo para os índice de excesso de precipitação e temperatura superior a $35^{\circ} \mathrm{C}$.

Em ambas as zonas de risco baixo, o cultivo da nogueira pecã pode ser implantado e cultivado, porém, recomenda-se especial atenção quanto aos índices determinantes nessas áreas, pois a sua influência será refletida na produção do cultivo. Indica-se atentar para as condições climáticas de cada região e associá-las ao tipo de solo, buscando desenvolver um sistema de manejo adequado com acompanhamento dos requerimentos nutricionais e fitossanitários, tipos de podas visando otimizar a produção da nogueira.

\section{Conclusões}

O Zoneamento de Risco Climático, síntese da integração dos cinco índices de risco, apresentou duas classes. A classe de risco muito baixo encontra-se em 41,8\% do território gaúcho e representa as áreas em que predominaram os índices de risco muito baixo ou a ausência de riscos. A zona com predomínio do risco baixo - A representa a maior parte do Estado, ou seja, 51,6\% da área total, e contempla as áreas com risco de estiagem ao sul e risco muito baixo a médio de falta de horas de frio. A classe de risco baixo - B destaca-se em uma pequena porção situada a noroeste do Estado, na fronteira com a Argentina, representa $6,6 \%$ da área total e se distinguiu da anterior pelo fato de apresentar o predomínio da falta das horas de frio.

O cultivo da nogueira pecã apresenta grande potencial para se desenvolver no Rio Grande do Sul, desde que observadas as áreas de restrições quanto aos riscos climáticos. A ocorrência dos riscos climáticos não significa que a nogueira pecã não poderá ser cultivada nestas áreas. No entanto, a incidência de fenômenos adversos para o cultivo poderá acarretar interferências, principalmente na produção. 


\section{Agradecimentos}

Agradecemos à FAPERGS (Fundação de Amparo à Pesquisa do Estado do Rio Grande do Sul) e à CAPES (Coordenação de Aperfeiçoamento de Pessoal de Nível Superior) pela bolsa de doutorado, e ao CNPq (Conselho Nacional de Desenvolvimento Científico e Tecnológico) pela bolsa de doutorado sanduíche da primeira autora (Processo nº 200592/2014-9).

\section{Contribuição dos autores}

O artigo é resultado da tese de doutorado em Geografia da autora Franciele Francisca Marmentini Rovani. A tese teve orientação direta do professor Cássio Arthur Wollmann. Para este manuscrito, coube à primeira autora fazer o delineamento do artigo segundo as normas da revista e a organização textual. Ao segundo autor, coube a função de revisar o artigo.

\section{Referências}

BRISON, F. R. Cultivo del nogal pecanero. México: CONAFRUT, 1976.

FRONZA, D.; HAMANN, J. J. Técnicas para o cultivo da nogueira-pecã. Santa Maria: Colégio Politécnico, 2016.

GRAGEDA, J. G. et al., El clima y la producción de nogal pecanero. XIV Simposio Internacional de Nogal Pecaneiro, México, 2013. pp. 55-66.

HEREERA, R.; GOLDBERG, N.; THOMAS, S. Diseases and other disorders of pecan in New Mexico. Guide H-657, nov. 2010, pp. 1-12.

HERTER, F. G. et al. Zoneamento agroclimático do pessegueiro e da nectarina para o Rio Grande do Sul. Documentos - 91, Pelotas, Embrapa Clima Temperado, 2002. pp. 27.

LAZAROTTO, M. Identificação e caracterização de Fusarium spp. E Pestalotiopsis spp. associados a Carya illinoinensis no Rio Grande do Sul. Tese de doutoramento. Universidade Federal de Santa Maria, Programa de Pós-Graduação em Engenharia Florestal, Santa Maria, 2013. 156 p. 
MAPA. MINISTÉRIO DA AGRICULTURA, PECUÁRIA E ABASTECIMENTO. Zoneamento Agrícola de Risco Climático: instrumento de gestão de risco utilizado pelo seguro agrícola do Brasil. 2010. Site<http://www.agencia.cnptia.embrapa.br/Repositorio/Zoneameno_agricola_ 000fl7v6vox02wyiv80ispcrruh04mek.pdf>, acessado em outubro de 2017.

MOTA, F. S. da; AGENDES, M. O. de O. Clima e agricultura no Brasil. Porto Alegre: SAGRA, 1986.

MOTA; F. S. da; ZAHLER, P. J. M. Clima, agricultura e pecuária no Rio Grande do Sul. Pelotas: Livraria Mundial, 1994.

POLETTO. T. et al. Fungos associados às flores e as sementes da nogueira pecã (Carya illinoinensis). Revista de Ciências Ambientais, vol. 8, n. 1, 2014. pp. 5-13.

RASEIRA, A. A cultura da nogueira pecã. Comunicado Técnico. Pelotas: EMBRAPA, nº 63, abr. 1990. pp. 3.

RIBEIRO, G. P. Tecnologias digitais de Geoprocessamento: Sistemas de Informação Geográfica (SIG). In: ARCHELA, R. S.; FRESCA. T. M.; SALVI. R. F. (Org.) Novas tecnologias. Londrina: Ed. UEL, 2001. pp. 1-12.

SENTElHAS, P. C.; ANGELOCCI, L. R. Temperatura do Ar como fator agronômico. Anotações de aula. Disciplina LCE 306 - Meteorologia Agrícola. São $\quad$ Paulo: $\quad$ ESALQ/USP, 2009. Site<www.lce.esalq.usp.br/aulas/lce306/Aula10.pdf>, acessado em março de 2017.

SIERRA, E. M.; LÓPEZ, E. L.; PÉREZ, S. P. Agroclimatología del pecán (Carya illinoinensis) em la Argentina. In: LAVADO, R. S.; FRUSSO, E. A. (Org.). Producción de pecán en Argentina. Buenos Aires: [s. n], 2007. pp. 1-10.

SPARKS, D. A. A Climatic approach to pecan scab control. Hort Technology, vol. 5, n. 3, 1995. pp. 225-230.

SPARKS, D. A. A Climatic Model for Pecan Production under Humid Conditions. Journal of the American Society Horticultural Science, vol. 121, n. 5, 1996. pp. 908-914.

SPARKS, D. A. A climatic model for predicting Georgia's pecan production.Proc. S. E. Pecan Growers Assn, v. 90, 1997. pp. $32-44$. 
SPARKS, D. A. Adaptability of Pecan as a Species. Hort Science, vol. 40, n. 5, 2005. pp. 1175-1189.

Rev. Bras. Cartogr., vol. 71, n. 3, julho/setembro, 2019. pp. 679 - 701 